\title{
Defining engineering: Learning from New Graduates to Expand the Image of Engineering
}

\author{
Lena Gumaelius \\ Dept. of Learning in Engineering \\ Sciences \\ $\mathrm{KTH}$ \\ Stockholm, Sweden \\ lenagu@kth.se
}

\author{
Marie Paretti \\ Dept. of Engineering Education \\ Virginia Tech \\ Blacksburg,Virginia, USA \\ mparetti@vt.edu
}

\begin{abstract}
To educate engineers for sustainable development, we need to help them develop an understanding of engineering work that positions sustainable development at the core of our field. But given the importance of prior knowledge and beliefs in learning, we first need to understand how students and new graduates currently perceive engineering work. To address this gap, we draw on data collected from the Capstone To Work project, that followed students from four U.S. institutions from graduation through their first year of work. In this initial exploration, we analyze responses from 76 graduating seniors and 36 early-career engineers regarding their definitions of engineering. Using thematic coding, we identified 9 different themes, which we then grouped under the three categories specified by Sinek's "golden circle" of marketing: what, how, and why. Most of responses fell into the "how" category and focused on problem-solving and design, echoing the prominent cultural narratives about engineering. But based on the findings here, we argue that engineering education would benefit from focusing more on the why-question when talking about engineers' role in society, both to better educate holistic engineers and to more effectively reach a wider audience.
\end{abstract}

Keywords-engineering work, early-career engineers, engineering education, engineering for sustainability

\section{INTRODUCTION AND BACKGROUND}

This full research paper explores perceptions of engineering work among new graduates. We argue that if we want to educate engineers for sustainable development, then we need to help them develop an understanding of engineering work that positions sustainable development at the core of our field. To do so, though, we need first to better understand how our graduates currently perceive their work.

Two strands of research frame this work. First, in recent decades, scholars have examined engineering identity among students [1-7]. For example, in his review of identity research in engineering, Morelock [1] identified eight "aspects of engineering" generated from studies of student perceptions: problem-solving, technical (math/science) knowledge, creativity and innovation, communication, ethics/integrity, positive social impact, lifelong learning, and application of knowledge. Godwin et al. [2], found that strong math and/or science identities and belief in engineering as a means to make positive change both increase the likelihood that individuals will pursue careers in engineers. In related work, Patrick et al. [3] in developing a measure of affect toward engineering practice based on attitudes among students and professionals, identified problem-solving, design, project management, analysis, collaboration, and tinkering as core aspects.

Second, scholars have sought to explore what practicing engineers actually do, predominantly via ethnographies and interviews [e.g., 4, 5-7]. As this work makes clear, engineering work is fundamentally socio-technical - that is, the application of technical (math and science) knowledge is inextricably bound to social interactions among colleagues, with supervisors, with clients, and with larger contexts.

Studies of practice, however, are more limited, and few have looked at how new engineers define engineering work once they enter the workplace. If we expect engineers to engage in sustainable development, we argue, then sustainable development and its associated practices should be central to students' conceptions of engineering work and to themselves as engineering professionals. To help develop such a mindset, though, research on learning [8] suggests that we need to first understand how new engineers currently see themselves and their work. That is, we need to understand their prior knowledge and beliefs.

To address this gap, we draw on data collected from a large multi-institution project, the Capstone to Work project, that followed students from four U.S. institutions from graduation through their first year of work. Participants were interviewed just prior to graduation and then at 3, 6, and 12 months of work, and the semi-structured protocol asked detailed questions about their occupation and professional role and the transition from higher education to work. Particularly relevant for this study, the interview protocol asked students to define "what it means to be an engineer and what engineers do." We use responses to this question prior to graduation and after 12 months of work to address the research question "How do recent engineering graduates describe engineering work?"

\section{METHODS}

Data for this study was drawn from the larger [removed for review] project. In this analysis, we draw on data from two separate cohorts: 76 interviews with senior engineering students conducted just prior to graduation, and 36 interviews with new engineers conducted after 12 months of work. Participants were recruited from four universities (three mechanical engineering 
programs and one engineering science program). The institutions are diverse in terms of size, focus (comprehensive, liberal arts, and science/engineering), and geographic region; full details are available in [9].

Semi-structured interviews exploring participants' transitions from their capstone design courses to work were conducted with each participant either in person (for seniors) or via video chat (for new engineers). Interviews lasted approximately 45-60 minutes. All interviews were audio recorded, transcribed verbatim, and de-identified prior to data analysis. In this study, we focus on participants' responses to the following question: "Engineering" is a really broad term that can mean so many different things to different people. Based on your experience so far, how would you describe what it means to be an engineer and what engineers do?

Data analysis proceeded in two phases. In phase one, the interviews were open-coded to identify emergent themes [10, 11]. The themes were then compared to existing literature to identify potentially useful frameworks to help categorize the themes in ways that could be meaningful to the larger goal of shaping students' understanding of engineering for sustainable development. To this end, we turned to an unconventional source: the business and marketing community. Specifically, we draw on Sinek's book, Start with Why [12], and its framework for reordering marketing and learning messages.

\section{FINDINGS}

\section{A. Emergent Themes}

The initial thematic coding process yielded nine themes, summarized in Table 1 and discussed in the following sections (participants are identified by ID number).

TABLE I. Percent of PARTicipants Mentioning EACH Theme

\begin{tabular}{|c|c|c|c|}
\hline Theme & $\begin{array}{c}\text { Graduating } \\
\text { Seniors } \\
(\mathbf{n = 7 6})\end{array}$ & $\begin{array}{c}\text { New } \\
\text { Engineers } \\
(\mathbf{n = 3 6})\end{array}$ & Average \\
\hline Problem solving & 59.2 & 33.3 & 50.9 \\
\hline Professional behavior & 28.9 & 13.9 & 24.1 \\
\hline Will to do good & 19.7 & 16.7 & 18.8 \\
\hline Design & 21.1 & 11.1 & 17.9 \\
\hline Engineering content & 6.6 & 2.8 & 5.4 \\
\hline Math and science & 13.2 & 11.1 & 12.5 \\
\hline Engineering thinking & 9.2 & 2.8 & 8.0 \\
\hline $\begin{array}{c}\text { Sustainable } \\
\text { Development } \\
\text { knowledge }\end{array}$ & & 5.6 & 1.8 \\
\hline Ethical thinking & 6.6 & & \\
\hline
\end{tabular}

Problem solving was the most frequently mentioned attribute participants used to describe engineering. In this theme, the participants often defined engineering with just that single term, or as one student said;

I know this sounds so cliché. I'm pretty sure everybody says it, but problem solving is the main thing that comes to mind. (4253).

Some participants did problematize this general term and depicted the problem-solving process as something more specific than just solving problems and recognizing that engineers are not the only ones that solve problems within their professions. They either refer to the context as being engineering-specific (e.g., an industrial problem needs to be solved), or as a problem where engineering-specific skills are needed (i.e. as problem solving where the use of scientific principles are involved in the solution).

Notably, although we do not claim statistical significance here, among our participants, graduating seniors were more likely to link engineering to problem-solving than engineers who had been working for a year, thought it was the most frequently mentioned theme for both groups.

The theme professional behavior encompasses attributes links to a range of professional skills, including interpersonal skills (communication, teamwork and management skills), timemanagement, and innovation. Time management emerged in terms of the expectation engineers should be efficient at work. Being innovative was described as both a personal trait and as something that is expected as part of an engineer's role. As one graduate says;

"I think it's (being an engineer) just to be innovative and to develop products, really." (1242)

Here, too, graduating seniors linked this theme to being an engineer more frequently than working engineers - particularly with respect to time management. While the working engineers did discuss time management in the context of their jobs more broadly in other parts of their interviews (see [9]), none included it in their response to the questions about what it means to be an engineer.

Design, often presented as a central component of engineering [13], was mentioned by only just over $20 \%$ of students and $11 \%$ of practicing engineers. This theme could refer to designing a product or a process, or more broadly to the design cycle used for producing technological interventions all the way from idea to a product on the market.

In addition to specific tasks and practices, participants described engineering thinking as a particular mindset or approach that identifies engineers and engineering, a theme that was often mentioned together with problem solving. That is, engineering thinking, developed during one's education, enables engineers to solve problems in ways that differ from other disciplines:

So, that was probably the biggest thing I've learned in school is that engineering like doesn't necessarily mean you remember all these theories and everything. It's just kind of how we think and what we've been taught to kind of, like the steps and the process. (4244)

Three of the themes are grounded in the description of the disciplinary knowledge needed for engineering. Several participants in both groups described engineering in terms of applying basic knowledge in mathematics and sciences. In a related theme, participants highlighted core engineering knowledge, which consists of a wide variety of knowledge that varied by discipline. Finally, some of the 12-month engineers also claimed that engineers need some basic knowledge of sustainable development; notably, none of the graduating seniors included sustainable development in their definitions. 
Participants also defined engineering in terms of its outcomes, specifically in terms of the will to do good. This theme collects the statements claiming that engineering is something that will have a positive impact in some way. Some participants describe the will to 'improve artefacts' that served a purpose for someone. Others described being able to "improve life," or 'people's lives,' the latter often related to achieving improvements in the health sector, as one graduating senior explained:

Engineering's about having a responsibility to serve the people that will be impacted by and using whatever project you are working on, whatever product you're trying to develop. And it's about improving lives, improving systems, and making things better. (1240)

Also, within this theme were participants who described engineering as the "possibility to improve the community around you" or, more broadly and holistically, to lead to "betterment for the world."

Related to this desire to achieve positive impacts, the last theme identified was ethical thinking. This theme referred to the way's engineers need to consider the consequences of their actions and the impact on both single individuals (e.g. within a work group) and to a whole community.

In summary, the theme most commonly referenced by our participants was engineering as problem-solving, though it was less dominant in the definitions provided by practicing engineers. The lack of a single overarching theme among the practitioners may reflect the wide range of workplaces that our participants entered. That is, while graduates across all sites generally experienced similar educational programs, those who were in their first year of work spanned a range of company sizes, sectors, job titles, and responsibilities, and thus show less uniformity in their descriptions of engineering work. Still, the definitions of engineering work our participants offered after their first year were similar to the ones offered by graduating seniors, even when the practitioners did not see their current work as engineering.

\section{B. Grouping the Themes: The Golden Circle}

To further explore these themes, particularly in the context of engaging engineering students in sustainable development work, we turned to the framework offered by Sinek [12], which he refers to as The Golden Circle (Figure 1).

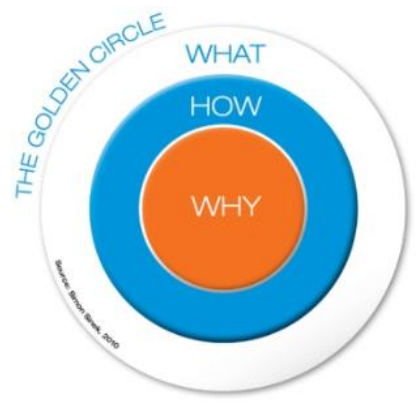

Fig. 1. Sineks model of successful marketing, the Golden Circle. [14]

This framework, developed in the context of marketing research, focuses on the parameters 'why', 'how', and 'what' for the product. Successful marketing, Sinek suggests, should always start with a focus on 'why' the consumer needs a specific product, followed by messages 'how' to achieve those goals, and ending with 'what' people should buy. Sinek argues that addressing why, i.e., the holistic purpose behind the product, first allows marketers to engage with consumers' emotions, which increases their likelihood of buying.

While marketing approaches may seem at odds with engineering, this focus on why also aligns with scholarly work on motivation highlighting the importance of utility value (i.e., usefulness in achieving goals) in undergraduates' career trajectories [e.g., 15, 16, 17]. And in fact, Sinek's model itself has been used to in education as a means to support learning [18]. Schmidt argues, for example, that students are more likely to be interested in learning the content of a specific course if they first understand and engage with the holistic goal(s) of the content and learning outcome(s). Beginning with the theory, Schmidt notes, and then slowly moving to the more holistic goals for learning, is a less successful teaching strategy with lower student motivation.

As a result, we used Sinek's model to categorize the themes developed in the previous section into three major categories, 'Why do we conduct engineering?', 'How is engineering conducted?', and 'What is engineering?'.

\section{1) Why do we conduct engineering?}

This category includes the themes describing the purposes of engineering actions and activities. It contains of two subthemes: will to do good and ethical considerations. Within the first subtheme, the statements express a positive agency and desire for achieving something good, whereas in contrast, the second subtheme describes a way of acting. This latter theme urges engineers to consider the consequences of their actions and minimize negative outcomes, regardless of whether those negative outcomes impact a whole community or only one human. These subthemes thus constitute two sides of the same coin where one describes the actual reason for conducting engineering and the other what to avoid with his/her engineering actions.

\section{2) How do we conduct engineering?}

Four themes were placed in this category: problem solving, personal behaviour, design, and thinking like an engineer. The themes in this category answer the question of how engineering work is done. In contrast to the declarative knowledge of the "what" themes, the themes grouped under how represent procedural knowledge or practices that participants aligned with engineering. The themes represent the ways in which engineers go about their work - the process of applying the declarative knowledge to achieve the end goals.

\section{3) What is engineering?}

In this category, we clustered the three subthemes describing the knowledge needed to perform engineering work: engineering core content, the link to math and science, and knowledge about sustainable development. Note that while sustainable development itself may be a "why," our participants talked about it in terms of knowledge they needed for their jobs, not goals they wanted to achieve. Thus, all three of these themes 
are grounded in the declarative knowledge needed for practicing engineering.

Table 2 summarizes these three categories, as well as the percentage of participants providing definitions in each group:

TABLE II. CATEGORIZATION OF THEMES

\begin{tabular}{|r|c|c|c|}
\hline Category & $\begin{array}{c}\text { Graduating } \\
\text { Seniors } \\
(\mathbf{n = 7 6})\end{array}$ & $\begin{array}{c}\text { New } \\
\text { Engineers } \\
(\mathbf{n = 3 6})\end{array}$ & Average \\
\hline $\begin{array}{r}\text { Why do engineering } \\
\text { Will to do good } \\
\text { Ethical thinking }\end{array}$ & $24 \%$ & $19 \%$ & $22 \%$ \\
\hline $\begin{array}{c}\text { How to do engineering } \\
\text { Problem solving } \\
\text { Professional behavior } \\
\text { Designing }\end{array}$ & $87 \%$ & $50 \%$ & $75 \%$ \\
$\begin{array}{c}\text { Engineering thinking } \\
\text { What is engineering } \\
\text { Engineering content } \\
\text { Math and Science }\end{array}$ & $16 \%$ & $17 \%$ & $16 \%$ \\
$\begin{array}{c}\text { Sustainable development } \\
\text { knowledge }\end{array}$ & & & \\
\hline
\end{tabular}

\section{DISCUSSION}

\section{A. Emergent Themes}

The 9 emergent themes from our analysis align closely with previous literature, with problem-solving and design in particular dominating the student responses. We note, however, that while these practices were still among those most frequently mentioned by new engineers after their first year of work, the percentage of participants citing them dropped considerably. That is, there appeared to be more commonality in the definitions of engineering among students than among professionals, potentially highlighting the significant variety in the kinds of jobs and the kinds of work engineers do once they leave school. Engineering as a profession may thus be far more varied than the images we present to students, and even seemingly "core" practices like problem-solving and design may not be as ubiquitous as engineering education suggests. This variation is particularly notably given that a majority of the participants were mechanical engineering graduates.

At the same time, we also note that professional behaviors (communication, teamwork, time management, innovation) are among the most commonly cited aspects of engineering. Though the absolute percentages are low, it was the second mostcommon theme among the graduating seniors and the third most-common among professionals. Its presence here is significant given the history of workplace research that suggests that engineers historically have viewed these practices as "not real engineering" $[4,19,20]$. Perhaps, more than a decade after Shuman et al. [21] argued that these professional skills can and should be taught, engineers themselves are slowly (very slowly) beginning to see them as integral to the profession.

\section{B. The Golden Circle}

When we examine the results in light of Sinek's Golden Circle, we see that most participants define engineering in terms of the 'how,' with $87 \%$ of the seniors and $50 \%$ of the new engineers focused on this aspect of engineering. The results suggest that by the time they graduate, students have moved beyond seeing engineering as the path simply for those who are "good at math and science" (the "what" that often draws students in - see, for example [22]), to conceptualizing the field more broadly in terms of the work of problem-solving and design, and even sometimes embedding those in social contexts.

At the same time, the more limited number of responses focused on "why" raise the possibility that engineering graduates have not been trained or invited to reflect upon the overarching goals of their profession, and that their workplace experiences further minimize or obscure those goals. If such a scenario is correct, then the engineering education community may need to reflect upon the image of engineering as a whole. If we are not creating educational and corporate cultures that help new engineers put "why" at the center of their understanding of the profession, then how would we expect our graduates to keep concepts like sustainable development at the forefront of their work? Moreover, how could we expect the public to move beyond conceptions of engineers presented (and mocked) in popular culture through shows such as "The Big Bang Theory"?

Sinek's work reminds us of the importance of positioning "why" at the center of the message in terms of marketing, but as Schmidt [18] and others argue, the "why" is equally important to learning and, we posit, to helping engineers beyond simply solving problems to solving particular kinds of problems that contribute to and support long term goals in sustainable development.

Certainly, the analysis here does not "prove" that new engineers do not care about or attend to the larger goals of engineering. Our interview protocol did not specifically ask them about the goals of engineering, and it is possible - perhaps even likely - that if asked, they might answer in terms associated with achieving public good in some way. Instead, we asked an open-ended question regarding participants' definitions of engineering and engineering work. And in that vein, the limited attention to underlying goals does at least raise questions about how these participants understand and conceptualize their chosen profession, and how that conceptualization aligns with the broader goals of preparing engineers for sustainable development.

This "why" seems particularly pressing as we write these closing paragraphs from the heart of the COVID-19 pandemic, where engineering labs at many universities are being repurposed to produce face shields, ventilators, and other equipment needed to help our communities - and particularly health care workers - combat the virus. Materials engineers are rapidly researching the effectiveness of various fabrics for masks; mechanical engineers are adapting and deploying their labs' fabrication equipment to rapid prototyping of new devices. Civil and environmental engineers are studying airborne agents, transportation systems, and more. Certainly, the crisis has highlighted the critical ways in which the "why" of engineering impels professionals across the subfields to contribute to pressing global needs. 


\section{CONCLUSIONS}

The definitions of engineering offered by the graduating seniors and new engineers in this study suggest that engineering itself is a highly diverse field, and even commonly invoked practices like "design" and "problem-solving" may not accurately capture the range of activities and practices involved in "being an engineer" or "doing engineering work." At the same time, the limited attention to the underlying goals of the field creating sustainable futures, contributing to public good, enhancing human life - suggest that neither our curricula nor our workplaces are promoting reflection centered on what motivates our profession.

Yet if we want to educate engineers for sustainable development, we argue that understanding this "why" is central to achieving that goal - to attracting more engineers to the field who value this goal, to educating them in ways that prepare them to apply their knowledge in service of that goal, and by creating cultures in which that goal is valued as a (the?) core of the field - across sub-disciplines and organizations and job functions.

\section{ACKNOWLEDGMENT}

This material is based upon work supported by the National Science Foundation under Grant Number 1607811. Any opinions, findings, and conclusions or recommendations expressed in this material are those of the authors and do not necessarily reflect the views of the National Science Foundation. The authors also wish to acknowledge all other researchers involved in the Capstone To Work project for their contributions to research design, data collection, and data management.

\section{REFERENCES}

[1] J. R. Morelock, "A systematic literature review of engineering identity: definitions, factors, and interventions affecting development, and means of measurement," European Journal of Engineering Education, vol. 42, pp. 1240-1262, 2017/11/02 2017.

[2] A. Godwin, G. Potvin, Z. Hazari, and R. Lock, "Identity, Critical Agency, and Engineering: An Affective Model for Predicting Engineering as a Career Choice," Journal of Engineering Education, vol. 105, pp. 312-340, 2016.

[3] A. D. Patrick, N. H. Choe, L. L. Martins, M. J. Borrego, M. R. Kendall, and C. C. Seepersad, " A Measure of Affect toward Key Elements of Engineering Professional Practice," in 2017 ASEE Annual Conference \& Exposition, Columbus, Ohio, 2017.

[4] J. Trevelyan, "Reconstructing engineering from practice," Engineering Studies, vol. 2, pp. 175-195, 2010/12/01 2010.

[5] J. Trevelyan and B. Williams, "Value creation in the engineering enterprise: an educational perspective," European Journal of Engineering Education, pp. 1-23, 2018.

[6] A. Vinson, P. Davis, and S. Reed, "Problem Solving in Engineering Education and Professional Engineering Work," presented at the 2017 ASEE Annual Conference \& Exposition, Columbus, Ohio, 2017.
[7] B. Williams and J. Figueiredo, "Finding workable solutions: Portuguese engineering experience," in Engineering practice in a global context: understanding the technical and the social, B. Williams, J. Figueiredo, and J. Trevelyan, Eds., ed Leiden, The Netherlands: CRC Press/Balkema, 2014, pp. 159-184.

[8] J. D. Bransford, A. L. Brown, C. R., M. S. Donvan, and J. W. Pellegrino, Eds., How People Learn: Brain, Mind, Experience, and School. Washington, D.C.: National Academy Press, 2000, p.^pp. Pages.

[9] M.C. Paretti, D.A. Kotys-Schwartz, S. Howe, J.D. Ford, B.D. Lutz, K. Kochersberger, C. Gewirtz, L.M. Rosenbauer and S. Arunkumar Collaborative Research: From School to Work: Understanding the Transition from Capstone Design to Industry, in American Society for Engineering Education Annual Confrence, Ohio, 2017, board \#116

[10] M. B. Miles, A. M. Huberman, and J. Saldaña, Qualitative data analysis: A methods sourcebook, 3rd ed. Thousand Oaks, CA: Sage, 2014.

[11] V. Braun and V. Clarke, "Using thematic analysis in psychology," Qualitative Research in Psychology, vol. 3, pp. 77-101, 2006/01/01 2006.

[12] S. Sinek, Start with why: How great leaders inspire everyone to take action. New York: Portfolio/Penguin, 2009.

[13] C. J. Atman, O. Eris, J. McDonnell, M. E. Cardella, and J. L. BorgfordParnell, "Engineering design education," in Cambridge Handbook of Engineering Education Research, A. Johri and B. M. Olds, Eds., ed Cambridge, UK: Cambridge Univ. Press, 2014, pp. 201-225.

[14] G. Llewelyn. (2011). The Golden Circle (licensed under creative commons). Available: https://www.flickr.com/photos/53682558@N06/6353289537

[15] B. D. Jones, M. C. Paretti, S. F. Hein, and T. W. Knott, "An analysis of motivation constructs with first-year engineering students: Relationships among expectancies, values, achievement, and career plans," Journal of Engineering Education, vol. 99, pp. 319-336, 2010.

[16] B. D. Jones, J. W. Osborne, M. C. Paretti, and H. M. Matusovich, "Relationships among Students' Perceptions of a First-Year Engineering Design Course and their Engineering Identification, Motivational Beliefs, Course Effort, and Academic Outcomes," International Journal of Engineering Education, vol. 30, pp. 1340-1356, 2014.

[17] H. M. Matusovich, R. Streveler, H. Loshbaugh, R. Miller, and B. Olds, "Will I Succeed In Engineering? Using Expectancy-Value Theory in a Longitudinal Investigation of Students' Beliefs," in American Society for Engineering Education Annual Conference, Pittsburgh, PA, 2008.

[18] S. J. Schmidt, "Embracing and Harnessing the Intimate Connection Between Emotion and Cognition to Help Students Learn," Journal of Food Science Education, vol. 18, pp. 87-96, 2019.

[19] K. J. B. Anderson, S. S. Courter, T. McGlamery, T. M. Nathans-Kelly, and C. G. Nicometo, "Understanding engineering work and identity: a cross-case analysis of engineers within six firms," Engineering Studies, vol. 2, pp. 153-174, 2010/12/01 2010.

[20] W. Faulkner, "'Nuts and Bolts and People': Gender-Troubled Engineering Identities," Social studies of science, vol. 37, pp. 331-356, 2007.

[21] L. J. Shuman, M. Besterfield-Sacre, and J. McGourty, "The ABET 'Professional Skills' - Can They Be Taught? Can They Be Assessed?," Journal of Engineering Education, vol. 94, pp. 41-56, January 20052005.

[22] J. J. VanAntwerp and D. Wilson, "Differences in motivation patterns among early and mid-career engineers," Journal of Women and Minorities in Science and Engineering, vol. 24, pp. 227-259, 2018-08-01 2018 . 